\title{
مؤتقرات علمية
}

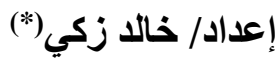

في مؤتمر أخلاقيات الإعلام بجامعة الشارقة:

(8) أوراق بحثية تحلل واقع الممارسة الإعلامية في العالم العربي

• دراسـة تقيس مدي إدراك طلبـة الاتصـال لأخلاقيـات الإعلام.. وآخري عن

التحولات في البيئة الإعلامية الجديدة البية

افتتح الدكتور حميد مجول النعيمي، مدير جامعة الثـارقة مؤتمر اأخلاقيـات الإعـلام وقو انينه في دول مجلس التعاون الخليجي《 الذي نظمته جامعة الثـارقة بالتعاون مـع مؤسسة الخليج للطباعة و النشر، ومؤسسة الثنارقة للإعلام. بدأ المؤتمر بكلمة الدكتور حميد مجول النعيمي، الذي أكد فيها إن الإعلام مهنة تقوم على معـايير أخلاقيـة وقانونيـة يتوجب على الإعلاميين دائمـاً التحلـي بها والالتز ام

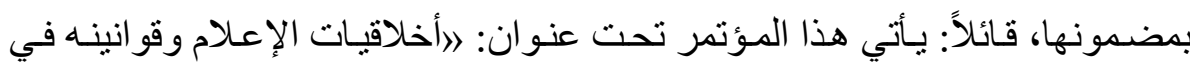
دول مجلس التعاون الخليجيه ليقدم رؤيـة لأسس الممارسـة الإعلاميـة الأخلاقيـة في دول الخليج العربية، وآفاقها المستقبلية، بما يخدم الإعلام المسؤول القائم على المبادئ الأخلاقية الإنسانية في الممارسات الإعلاميـة المعاصرة، من خـلال مـا سيطرحه من محاور علمية تبحث في مو اثثيق الثرف و الضو ابط الأخلاقيـة لمعالجـة وسـائل الإعـلام للصر اعات، ووسائل الإعلام وبناء السلم المجتمعي، فضلاً عن الخصوصية الفرديـة، و الملكيـة الفكريـة، وجر ائم الإنترنـت، و العنف في السينما و التلفزيـون، وغير هـا مـن

(') 'لمدرس المساعد بقسم الصحافة ـ كلية الإعلام - جامعة القاهرة 
المحاور ، كمـا يقدم در اسـات في الصـحافة، و الإذاعـة والتلفزيون، و العلاقـات العامـة، و الإعلان، ووسائل التو اصل الاجتماعي.

و أشــار إلـي أن غيـاب الانضـباط الأخلاقي أو تضــاؤله، على مسـتوى وعـي الفـرد وضمبره والواجب الأخلاقي وتغليب الجانب التجاري و الدعائي في المجال الإعلامي عامـة، دفـع النقاد إلى التسـاؤل عمـا إذا كـان الإعـلام مهنـة بضـوابط مهنيـة وأخلاقيـة وقانونية محدة على غرار الطب و القانون.

مـن جـانبهم، أنتـاد المتحدثون الرئيسيون: الدكتور كريستيان كليفورد أستاذ الإعـلام بجامعـة إلينوي في الولايـات المتحدة، والدكتور عبد الرحمن العنـاد أستاذ الإعـلام ومستشـــار مركـز أسـبـار للار اســات و البحـوث الإعلاميـة، بـالمؤتمر وموضــوعه وبمستوى التنظيم، مؤكدين أهمية المحاور و المواضيع التي تتناولها جلسـات المؤتمر. وركـزت الجلسـات علـى عـدة موضــوعات أهمهـا: الضــو ابط الأخلاقيـة للممارسـة الإعلامية على مدار جلستين، أدار همـا الدكتور خالد المدفع و الدكتور عصدام نصر ،

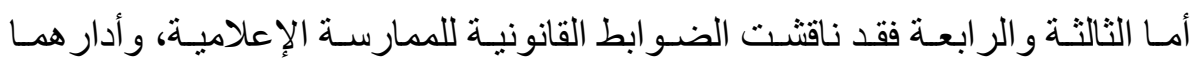
الدكتور خيرت عياد والدكتور صـالح أبو إصبع، وكرّم المتحدثين و الثـركاء على هامش المؤتمر مدير الجامعة.

\section{الضوابط الأخلاقية للممارسة الإعلامية}

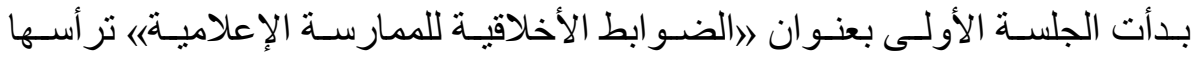
الدكتور خالـد المـدفع، و استتهل الحديث الدكتور محمد عـايش الأستاذ في الجامعـة الأمريكيـة بالثـارقة، متحدثناً عن تدريس أخلاقيـات الإعـلام في الجامعـات العربيـة. و أكد أن الأخلاقيـات تعـد مـن أهـم المـداخل المسـتخدمة في در اسـة وممارسـة العمـل الإعلامي في المجتمعات الحديثة، ومن بينها المجتمعات العربية، في ضـوء الحاجـة الملحسة إلـى ضــو ابط و اضـحة تسـهم في تمكين الإعلاميسين ومؤسســاتهم مـن اتخـاذ 
القر ار ات المناسـبة و الصـائبة أثثـاء تـأديتهم لعملهم بعيـاً عـن إلحـاق الأذى بأنفسـهم وبالآخرين من حولهم.

وأثــار إلى أنـه رغم أن المقررات الار اسية في الجامعـات العربيـة تتضـمن مكونـات أخلاقية مهمة في الإعلام والاتصال الجماهيري، فإن تلك المقرر ات تعاني مشكلات عدة، تتمثل في اعتمادها المفرط على المنهج المعياري و الوصفي على حساب المنهج النظري و التحليلي المستند إلى الممارسـات الإعلاميـة الحقيقيـة في الفضــاء الاتصـالي العربي.

وحث الدكتور عايش على ضرورة وجود دبلوم عال لتدريس الضو ابط الأخلاقيـة في العمل الإعلامسي أسوة بكلية الإعلام بجامعة القـاهرة، وضرورة العمل على تطوير النظريـات الأخلاقيـة العربيـة في الحقل الإعلامسي، لتسـتمد روحهـا ومفاهيمهـا مـن المنظومـة العربيـة الإسـلامية و الممارسـات المهنيـة الحديثة في الإعـلام، فضـلاً عن التفاعل البنـاء مـع المؤسسـات الإعلاميـة وممارسـي العمـل الإعلامسي مـن المهنيبن، لإثر اء المناهج الدراسية والعمليـة التعليميـة بأفكار هم ورؤاهم عن أفضل الممارسـات الإعلامية الملائمة للبنية الأخلاقية العربية. إدراك طلبة الاتصال لأخلاقيات الإعلام وقدم خلال الجلسة الدكتور عصام نصر الأستاذ بكلية الإعلام جامعة القاهرة، و عميد

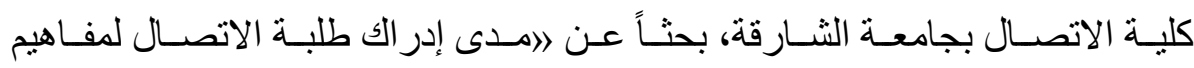
أخلاقيات الإعلامها. قائلاً: إن البحث يسعى إلى التعرف علي اتجاهات دارسي الإعلام نحو درجة أهمية أخلاقيات الممارسة الإعلامية على كل المستويات، كمـا يسعى إلى الى قياس مدى إدر اكهم سو اء منهم من درس ميثاق أخلاقيات الإعلام أو من لم يدرسه بعد إِ المفـاهيم وأسـس أخلاقيـات الإعـلام بغـرض عقد مقارنـة تظهـر مدى أهميـة تـدريس 
الميثاق بصـورته الحاليـة ومدى الحاجـة إلى تطويره، تماثـياً مـع تطور الممارسـات الإعلامية ووسائل الاتصال نفسها وتغير ها.

و أثنار إلى أن البحث اعتمد على در اسة ميدانية على عيّنة من 200 طالب وطالبة من دارسي الاتصال في الجامعة، نصفهم ممّن درسو ا ميثاق أخلاقيات الإعلام، و النصف الآخر لم بدرسه بعد.

وتتاولت الدراسة عدة موضو عات من بينها المسؤولية الاجتماعية في وسائل الإعلام، الحقيقة و الدقة، الأخلاق العالمية و العولمة الإعلامية و الاقتصادية و الثقافية، إلى جانب

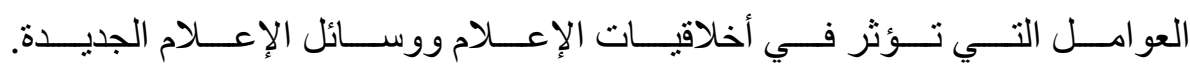
وخلصــت الدر اسـة إلـى مجموعـة مـن النتـائج التـي عكسـت مـا نعيثــهـ مـن عصـر المعلومـات و الإعـلام بمسـتجداته المتلاحقـة التـي تتطلـب مو اكبتهـا وتقيـيم معايير هــا المهنية، بما يتو افق مع تر اثنا وثقافاتنا وهويتنا الوطنية.

\section{دراسة التزام السعوديين بالصحف الإكترونية}

وبعدها قدم الدكتور عبد النبي النوبي، أستاذ الصـحافة في جامعـة جـاز ان بالمملكة العربية السعودية، دراسة عن مدى التزام الصحفيين السعوديين العاملين في الصحف

$$
\text { الإلكترونية بالضو ابط الأخلاقية للنشر الصحفي. }
$$

و أنتار إلى أن اختيار هذا المجال جاء لأسباب عدة، منها انتشـار الصحافة الإلكترونيـة في المملكة العربيـة السـعودية، وازديـاد اهتمـام الجمهور بهـا، فضـلاً عن أن طبيعـة الصحافة الإلكترونية تجعلها أكثر حرصـاً على السبق الصحفي، مـا بقلل من فرصـة تأكدها من مصداقية أخبار ها.

وتسـى الدر اسـة إلى تحقيق أهداف عدة، ومنها تحديد أكثر المـواد مخالفـة لضـوابط النشر التي تقع فيها الصحافة الإلكترونيـة السعودية، والوصسول إلى معايير أخلاقيـة للنشر الصحفي، من خلال وجهة نظر الصحفيين السعوديين. 
أخلاقيات المهنة والتحولات الجديدة

فيما تحدث الدكتور العربي بو عمامة، مدير مختبر در اسات الاتصسال و الإعلام بجامعة عبد الحميد بن باديس مستغانم الجزائر، عن أخلاقيات المهنة الصحفية والتحو لات في البيئة الإعلامية الجديدة.

وقال إن العصر الراهن يتسم بالعديد من المتغير ات المتسار عة و الثور ات التكنولوجية

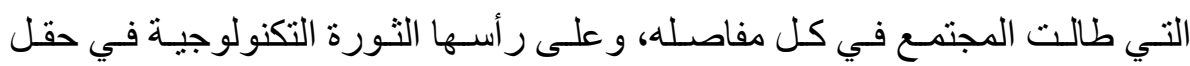
التو اصل الإنسـي، مشيراً إلى أنها أحدثت تغيرات مفصلية في طبيعـة الممارسـات

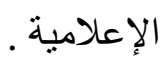

وأضاف أنه بالر غم من تغير خريطة تكنولوجيا التو اصل وتأثير هـا في بيئة ومنظومـة الممارسة الإعلامية في العالم، فإنه يتعين على الصحفي أن يتمسك بمبادئ و أخلاقيات المهنة الصحفية مع ممارسة حقه في الاتصال و الوصول إلى المعلومات. واختتم الجلسة الدكتور علي أحمد المهداوي، أستاذ القانون بجامعة الثـارقة بالحديث عن أخلاقيـات الإعـلام في ميزان الحقائق وهي در اسـة من منظور إسـلامي فلسفي،

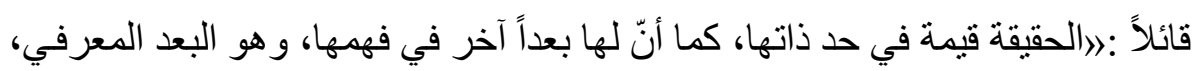

$$
\text { و أخراً في تكوين أو تصوير أخلاقي في نفس المتلقي. }
$$

وبدأت الجلسة الثانية برئاسة الدكتور عصام نصر ، وقام الدكتور خيرت عياد، رئيس قسم العلاقات العامة بجامعة الثـارقة در اسة بعنوان "أخلاقيات معالجة وسائل الإعلام

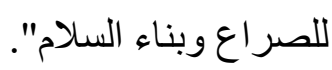

و أكد أن الدراسـة تسـى إلى تحديد البعد الأخلافي لدور وسـائل الإعلام في معالجـة الصر اعات والتباينات الثقافية والاجتماعية والسياسية داخل الدول، بما يضمن الحفاظ 
على رأس المال الثقافي و الاجتماعي، ويسهم في بناء السلم المجتمعي، مشيراً إلى أنه وفقا للتحليل الوظيفي يميز الباحثون بين سبع وظائف أساسية تؤرخ لتطور الدور الذي يمكن لوسائل الإعلام أن تقوم بـه لبنـاء السلم المجتمعي ومنع العنف والصـر اع و هي: وظيفة وسائل الإعلام مصدر اً للمعلومات، ووظيفتها في مر اقبة البيئة لرككلب

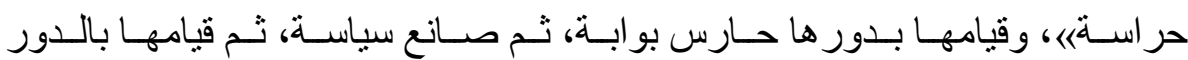
الدبلوماسي، ثم وظيفتها داعماً للسلام، ودور ها صانع سلام.

\section{أخلاقيات التغطية الإخبارية}

وقدمت الدكتورة رباب عبد المنعم التلاوي، أستاذة الصحافة في كلية الآداب بجامعة

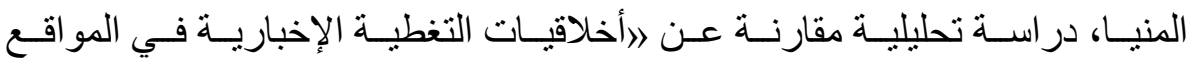
الإلكترونية الإخبارية العربية والمصرية".

و أكدت أن أهمية هذه الدر اسة تأتي في تتاولها لموضوع أخلاقيات التغطية الإخباريـة في المو اقع الإلكترونية الإخباريـة، حيث فتح الإنترنت مجالاً كبيراً للعمل الإعلامي

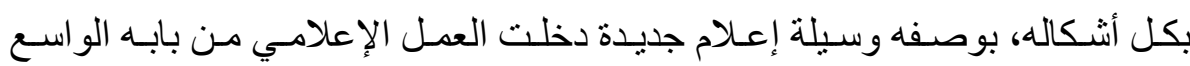
وحققت انتشار آ كبيرًا. وتهـدف الدراســة إلـى تقيـيم مـدى التـزام المواقـع الإلكترونيــة الإخباريــة العربيـة و المصرية بالأخلاقيات المهنية والإعلاميـة في تغطيتها الإخباريـة، وأثـارت إلى أنهـ يتوجب لتحقيق هذه الأهداف الإجابة عن التساؤلات:هل هنالك ميثاق أخلاقيات للإعلام الإلكتروني بشكل عـام، وللمواقـع الإخباريـة بشكل خـاص، يؤدي إلى الارتقاء بأدائهـ المهنـي و الإعلامسي؟ فضـلاً عن مدي التز ام المواقـع الإخباريـة العربيـة و المصـرية بأخلاقيات العمل الإلكتروني. 


\section{تفاعل القرّاء مع "الخليج الإكترونية"}

وقدمت الدكتور رقيـة بوسنان، أستاذة الإعـلام في جامعـة الأمير عبد القادر للعلوم الإسلامية بالجزائر، بحثناً بعنوان 》أخلاقيات تفاعل القراء مـع المحتوى الإعلامي في صحيفة الخليج الإلكترونية/)، وقالت إن الصحافة الإلكترونية تعدّ شكلاً اتصـالياً حديثاً

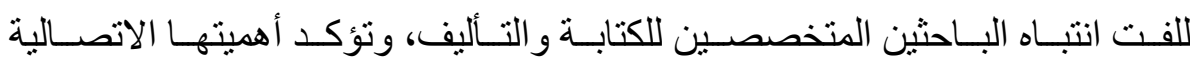
و الإعلامية، لأنها مرتبطة بالثبكة العنكبوتية ذات الخصائص المتميزة. و أضـافت أن البـاحثين اتفقـوا على أن الصـحافة الإلكترونيـة أعطـت للأفـر اد حريــة التصفح الإلكتروني و التعليق و التعبير عن وجهات النظر، عمّا ينشر من معلومـات ومو اد في مجالات متعددة سياسية، اقتصادية، أخلاقية، وثقافية، ورياضية، كما وفرت

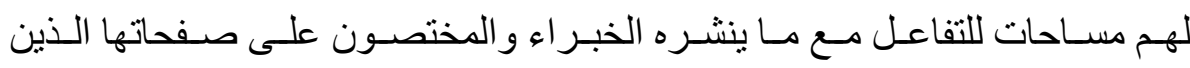
يستخدمون مختلف القو الب الفنية والأساليب لإقناع الفرد.

و أثـارت إلى أن مو اقف الأفر اد تتعدد و اتجاهاتهم نحو مـا تقدمه الصحافة الإلكترونية من محتوى على مستوى الثكل و المضدون، لتتحول إلى تعليقات إيجابية أو سلبية، يفترض أن تخضع لمعايير أخلاقيـة تبتعد عن العنف اللفظي و التقييم الجـار ح لمـا هو مقدم.

وقدم الـدكتور رضــا أمسين، أسـتاذ الإعـلام المشـارك فـي الجامعـة الأهليـة، بمملكـة البحرين، بحثناً عن الضو ابط المهنية و الأخلاقية للعمل الإعلامي بين نصوص التشريع

$$
\text { ومواثيق الثرف بمملكة البحرين. }
$$

وقـال إن التشـريعات القانونيـة ومواثيتق الثـرف الإعلاميـة تسـعى إلـى وضـع إطــار تنظيمي و أخلافي للممارسة الإعلامية، مشيراً إلي أنها لابدّ أن تتو اكب هذه التشريعات و المو اثيق مـع مستجدات البيئة الاتصـالية التي تتسـم بأنهـا متلاحقة التغير و التطور، حتى تؤدي دور هـا بفعاليـة، لتحقيق التوازن بين النظـام الإعلامسي من جهـة و النظم 


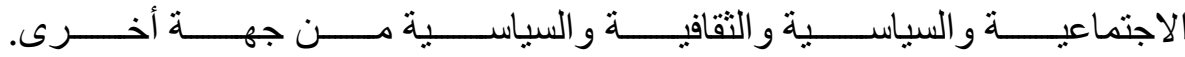
وتهـدف الدراســة إلى التعـرف علـي البنـود التنظيميـة التـي يوفرهـا كـل مـن الجانـب القانوني و المو اثيقي بالمملكة، وكذللك التعرف علي مدى ملاءمتهـا للبيئة الاتصـالية

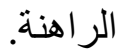

وتحساول الدر اسـة الإجابـة عن التسـاؤلات مـا الضـو ابط المهنيـة التي توفر هـا القو انين المنظمة للعمل الإعلامي في مملكة البحرين، فضـلاً عن الجهات التي أطرت لميثاق الثرف المهني للإعلاميين في مملكة البحرين. مبادئ معالجة قضايا حقوق الطقل العربي واختتمـت الجلسـة بحديث الأسـتاذة إيمـان بهـي الـدين، مـديرة إدارة إعـلام الطفولـة، المجلس العربـي للطفولـة والتنميـة بجمهوريسة مصر العربيـة، التي عرضـت تجربـة المجلس العربي للطفولـة والتنميـة في إعداد المبادئ المهنيـة لمعالجـة الإعلام العربي وقضـايا حقوق الطفل العربي، وتهدف إلى أن يسترشـ بها الإعلاميون العرب في

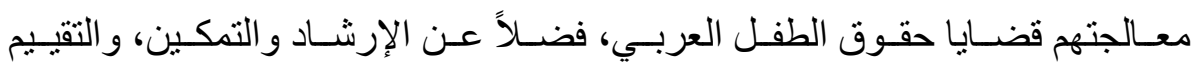
و التشـخيص، وصـو لاً إلى تطوير هـا الأداء الإعلامسي إيجابيـاً، وبمـا يجعلـه صـديقاً للطفولة.

و أضـافت أن المبـادئ المهنيـة ترنو إلى إعـلام يحترم حقوق الطفل، وتدعم حقهـ في الحماية من العنف والاستغلال، ومنظومة قيم ترتكز على المهنية والتمكين والمو اطنة و العدل الاجتماعي و الحرية و الثفافية. 